\title{
PROFESSORA EMÉRITA: discurso para a cerimônia de outorga do título
}

\section{Barbara Freitag-Rouanet*}

Magnífico reitor da Universidade de Brasília, Professor Timothy Mulholland.

Prezado vice-reitor, professor Edgar Mamiya.

Prezada diretora do Instituto de Ciências Sociais, Lourdes Maria Bandeira.

Queridas Astrid Berlindes Küchelmann e Mariza Veloso, as amigas e colegas da Chefia do Departamento de Sociologia.

Meus caros membros da Comissão de Honra.

Colegas, professores, alunos e funcionários aqui presentes.

Minha querida família vinda de perto e de longe.

Minhas senhoras e meus senhores.

Sinto-me profundamente honrada com a distinção que esta Universidade, fundada por Darcy Ribeiro, hoje me concede, agraciando-me com o título de Professora Emérita.

Como sabem, trata-se de um título que se concede aos professores aposentados que "tenham alcançado uma posição eminente em atividades universitárias", como se pode ler no site da UnB.

Algumas pessoas já me deram os parabéns por esse título, afirmando que eu o "merecia". Mas o que significa "merecer" um título?

Professora aposentada, pesquisadora associada do Departamento de Sociologia da Universidade de Brasília (UnB). 
Até agora, todos os títulos acadêmicos que possuía foram adquiridos, conquistados pelo estudo, pelo exame, por seleção e em concurso público. Ninguém obrigou-me a entrar na universidade, ninguém cobrou de mim que fizesse além da graduação, o mestrado, doutorado ou pós-doutorado, ou até mesmo a Habilitation. Talcott Parsons chamaria isso de achievement, qualidades e características alcançadas por esforço próprio, em contraponto com algo que nos é dado, conferido, por um capricho da natureza, ou por um mero acaso, o que o sociólogo americano chamou de "ascription”, em todo caso, algo que independe de nossa vontade e intervenção.

Esse novo título de Professora Emérita não cai em nenhuma das duas categorias: não nasci com o título e nada fiz para obtê-lo. Recebi-o de certa forma gratuitamente, dado de presente, sem que o solicitasse, mas que me foi conferido pela instituição à qual estive filiada por mais de 30 anos como reconhecimento de minhas atividades profissionais. Por esse reconhecimento - que não esperava -, sou especialmente grata aos membros da UnB que o exprimem com essa outorga do título de Professora Emérita.

Sempre distingui a nossa carreira universitária da carreira diplomática no Brasil, em que muitas vezes as "promoções" e "remoções" dependem de favores políticos, simpatias dos superiores hierárquicos e da conjuntura de poder do momento, enquanto a carreira universitária basicamente se pauta na competência, no saber, na busca da verdade, na compreensão dos fatos.

Sempre preferi a "carreira universitária" que independe de "esquemas", "pistolões", favoritismos, nepotismos. Mesmo em tempos politicamente difíceis como a ditadura militar, em que a universidade sofria patrulhamento ideológico e formas abertas ou veladas de censura, o sistema acadêmico era poroso: editoras e jornais tinham a possibilidade de "promover" intelectuais, escritores, pensadores, professores, lançando suas idéias, teses, pesquisas, publicando-as sob forma de livros, ensaios e artigos, no "espaço público" (como diriam Kant e Habermas). São formas de valorização do professor universitário que se dão por outras vias, não pela academia local mas 
sim pelo mercado livreiro e por agremiações extra-universitárias. Há, pois, diferentes modalidades de burlar sistemas universitários autoritários e ganhar leitores, seguidores, eventualmente "fama" pela arma da palavra, pela livre disputa de idéias, fora de conjunturas políticas opressoras.

Gostaria de introduzir aqui outra polaridade, mais antiga que a de Parsons e que, no fundo, traduz a mesma idéia do sociólogo americano. Trata-se da dicotomia virtù $x$ fortuna, devida a Maquiavel.

A virtù tem a ver com o esforço individual e a fortuna, com os fatores externos que estão fora do nosso controle.

Nem tudo depende da virtù do professor para moldar e consolidar sua carreira. Sem fortuna, o trabalho docente poderia transformar-se em uma cruz. Necessitamos o que Bourdieu chamou de "capital cultural", que adquirimos pelo empenho de nossos pais, irmãos, avós e professores (do curso primário aos cursos universitários). Mas, enquanto professores e pesquisadores, necessitamos também de apoio institucional e financeiro. Obtive esse apoio de instituições alemãs (como o DAAD e DFG) e brasileiras (como Capes, CNPq, Inep, UnB).

Além disso, enquanto professores, necessitamos de uma "fortuna" muito especial: da sede de saber de nossos alunos, de sua simpatia, de seu respeito, de sua amizade. Posso dizer que tive muita "fortuna" nesse sentido. E quero agradecer aqui a todos que foram alunos e colegas meus, fazendo de mim uma professora, realizada em minha Vocação/ "Beruf”. Tanto em alemão quanto em português, há aqui a dupla conotação de profissão (a ser exercida) e de chamamento pelo bom desempenho do professor, sem o qual o exercício da atividade docente é impensável.

Trinta e cinco anos de docência tornaram-me "afortunada", rica em saberes mediatizados pelas perguntas e provocações dos meus alunos, "afortunada" em amigos, antigos alunos, "afortunada" em colegas que levaram minhas preocupações profissionais e teóricas 
adiante, valorizando os ensinamentos morais, filosóficos e sociológicos que lhes tentei repassar.

Gostaria de exemplificar isso com duas iniciativas que partiram de antigos alunos, hoje professores e pesquisadores ou profissionais consagrados.

Um dos exemplos remonta ao início de minhas atividades na UnB, como recém-doutora vinda da Alemanha, em 1972, para lecionar na pós-graduação. A minha primeira turma de alunos compunha-se de diplomatas e jovens professores. Essa turma mostrou-me o que Humboldt quis dizer com "unidade do corpo docente e discente". No caso, não se trata de um mero diálogo, mas uma interação permanente na relação entre quem ensina e quem aprende. Aprendi a valorizar o capital cultural dos meus alunos que me ensinaram três coisas importantes: 1) que nossos alunos (e filhos) são nossos melhores professores; 2) que minha verdadeira vocação consistiria em desenvolver o ensino e a pesquisa na comunidade acadêmica da UnB; 3) que encontraria no Itamaraty um dos intelectuais e diplomatas mais fascinantes: Sérgio Paulo Rouanet. "Aproxime-se logo dele", foi o conselho de uma das integrantes do curso, "antes que outras aventureiras o façam" (!), organizando um jantar para que nos conhecêssemos. Segui à risca esse ensinamento. Sérgio e eu comemoraremos, em breve, 33 anos de "Gemeinsamkeit" e felicidade.

O segundo exemplo aconteceu pouco antes da minha aposentadoria. Em 2002, vários colegas e ex-alunos, homenagearamme, neste mesmo auditório, com um Seminário intitulado "Itinerários de Barbara Freitag", que até virou livro, para festejar os meus 60 anos que coincidiam com meus 30 anos de ensino na UnB. Foi algo inesperado, gratuito, demonstrando a "fortuna" da qual estou falando. Devo esse presente a todos os participantes do seminário e especialmente aos organizadores, Nair Bicalho, Maria Francisca e Sérgio Paulo Rouanet. O Seminário consistia numa espécie de leitura crítica, por parte dos convidados, de minha "obra". No final das palestras, os organizadores deram-me a oportunidade de responder, 
contestar, corrigir, aceitar (ou não) a interpretação que tinham feito dos meus textos.

Foi um dia de adrenalina pura, em que me senti em um labirinto de espelhos. Todos eles refletiam uma de minhas várias facetas intelectuais, políticas e pessoais.

No contexto desse Seminário, foi feita a pergunta: "Afinal, como doutora alemã, titular no Brasil, palestrante em universidades européias, pesquisadora em vários países latinoamericanos, a que margem do rio você pertence?" Respondi espontaneamente: "A nenhuma, pois sou 'Ponte'!'

A ponte pode ser vista como sendo a metáfora da "mediação" (Vermittlung), do diálogo e da dialética. Como pertenço, simultaneamente, ao continente europeu e latinoamericano, à cultura alemã e à brasileira e estando inserida em duas tradições lingüísticas, a germânica e a latina, encontrei meu itinerário acadêmico de "mediadora" traçado de antemão: levar o pensamento sociológico alemão para o Brasil e trazer para a Alemanha as interpretações do Brasil feitas por sociólogos e cientistas sociais brasileiros como Gilberto Freyre, Celso Furtado e Florestan Fernandes. Assim, divulguei "A teoria Crítica da Escola de Frankfurt" em Brasília, São Paulo e Salvador (no final do mês darei curso na Federal do Paraná sobre este tema). Do mesmo modo, levei para Berlim, Zurique, Copenhague e Praga o pensamento dos autores de "Casa Grande e Senzala", a "Integração do negro na sociedade de classes" e a "Formação do Brasil".

Como discípula de Adorno e Horkheimer sabia, no entanto, que, entre tese e antítese, a síntese seria impossível. Aceitei a polarização e a diferença, tentando construir pontes para superá-las. Admito que por vezes construí pontes sobre rios cujos leitos secaram e não cheguei a tempo para evitar que o rio inundasse praias amigas, onde deixei algumas construções pela metade...

E houve tempos em que permaneci aparentemente sumida, na “terceira margem do rio", para falar com Guimarães Rosa. 
Do meu amigo e mentor intelectual, responsável por minha volta ao Brasil, Florestan Fernandes, aprendi que ensinar e pesquisar faz parte de uma obrigação para com aqueles que não tiveram as mesmas facilidades e "mordomias" para estudar que tive pessoalmente.

Quando certa vez me queixei de estar "frustrada" com a universidade no Brasil, levei um puxão de orelha: "Sentir-se frustrada é questão de menina mimada da burguesia!" E Florestan mandoume voltar ao trabalho com a advertência: "E nada mais de lamúrias!" Weber, seu colega alemão, teria dito: "Erfülle die Forderung dês Tages" (Faça o que o dia cobra de você, estude, pesquise, publique!). Segui os conselhos desses grandes mestres e tentei repassá-los aos meus alunos e leitores.

Ao aposentar-me não deixei a universidade. Continuo trabalhando, pesquisando, lecionando, hoje certamente com menos certezas que antes. Entre as convicções das quais nunca abri mão estão as mais simples e mais elementares: 1) defender com unhas e dentes a liberdade acadêmica que inclui a liberdade de ensino e pesquisa; ou seja, não admitir jamais patrulhamento ideológico dentro da Universidade: seja de caráter político (como ocorreu durante a ditadura militar), seja de caráter religioso ou étnico (como está ocorrendo atualmente no contexto do debate das "cotas"); 2) defender a comunidade acadêmica e nela, a unidade de docentes e discentes; e, 3) praticar sempre o elo inseparável entre ensino e pesquisa. É o que aprendi com o reformador da universidade alemã: Wilhelm Von Humboldt.

Se o título de Professora Emérita contempla esses valores, universalizando-os para todos que me sucederão, então, efetivamente, mereci esse título. Por isso, mais uma vez o meu muito obrigada a todos que me ajudaram a recebê-lo.

Rio/Brasília, março de 2006 